\title{
ALGORITHM TO CALCULATE SUSPENDED SEDIMENT CONCENTRATION USING LANDSAT 8 IMAGERY
}

\author{
HernándeZ-CruZ, B..$^{1 *}$ - VÁsqueZ-Ortiz, M. ${ }^{2}$ - CANET, C. ${ }^{3}$ - Prado-Molina, J. ${ }^{4}$ \\ ${ }^{1}$ Facultad de Ingeniería, Universidad Nacional Autónoma de México, Ciudad Universitaria, \\ Coyoacán, C. P. 04510, Ciudad de México, Mexico. \\ ${ }^{2}$ Instituto Nacional de Pesca y Acuacultura, SAGARPA, Av. México 190, Del Carmen, \\ Coyoacán, C. P. 04100, Ciudad de México, Mexico. \\ (e-mail: Mariogeo190192@gmail.com) \\ ${ }^{3}$ Centro de Ciencias de la Atmósfera, Universidad Nacional Autónoma de México, Ciudad \\ Universitaria, Coyoacán, C. P. 04510, Ciudad de México, Mexico. \\ (e-mail: ccanet@atmosfera.unam.mx; phone: +52-55-5622-4059; fax: +52-55-5622-5009) \\ ${ }^{4}$ Laboratorio Nacional de Observación de la Tierra, Universidad Nacional Autónoma de \\ México, Ciudad Universitaria, Coyoacán, C. P. 04510, Ciudad de México, Mexico. \\ (e-mail: jprado@igg.unam.mx; phone: +52-55-5623-0222 ext.45475) \\ *Corresponding author \\ e-mail: gberehc@ingenieria.unam.mx; phone: +52-55-5622-8001ext.1028 \\ (Received 24 $4^{\text {th }}$ Jan 2019; accepted $10^{\text {th }}$ Apr 2019)
}

\begin{abstract}
Satellite imagery was used to assess the suspended sediment concentration (SSC) of the plume at the Grijalva river mouth, Gulf of Mexico. The SSC was calculated with the algorithm of Topliss. The algorithm was created for Lansdast 5 MSS. For this study it was validated the results for Landsat 7 ETM+ and Landsat 8 OLI. The depth of the ocean floor was measured using the speedtech sounder. The spectral response was registered with a GER-1500 spectroradiometer (with a measurement range of 296.71-1092.08 nm). The spectral responses were used to determine the size of the suspended particles and to perform the atmospheric correction. Spectral responses indicate that silt size particles predominate near the river mouth, whereas clay overtakes further towards the open sea. The trend in the river when water meets seawater, means an increase of suspended sediment towards the surface due to the lower density of fresh water, and the amount of sediment rises in the open sea. The correlation between the measurements in situ and SSC values produced by the algorithm demonstrates that the operation is suitable to estimate suspended sediments.
\end{abstract}

Keywords: Grijalva River, spectral response, sediments decrease, particles size, speedtech sounder

\section{Introduction}

Suspended sediments in the plume of a river mouth control the delta morphology and ecology. In water bodies suspended sediments are quantified as a concentration, as the total amount of solids suspended in the mixture water-sediment, generally expressed in mg/l (Carbonneau and Piégay, 2012; Qu, 2016).

The importance of the study of suspended sediment concentration (SSC) in the delta and sediment plume of the Grijalva River, southwestern Gulf of Mexico, lies in the volume of water transported $\left(140 \mathrm{~km}^{3}\right.$ per year; the river length: $\left.1521 \mathrm{~km}\right)$, and the vulnerability that it represents in physical-geographic terms (Kemp and Piégay, 2016). A serious vulnerability issue in the delta is the coastline retraction; this phenomenon occurs at the State of Tabasco, southern Mexico, from Sanchez Magallanes (3 to $5 \mathrm{~m}$ 
per year) to the mouth of the San Pedro River, with 8-9 m per year (Hernández et al., 2008; Nooren et al., 2017).

The assessment of SSC could be done with sensors capable of detecting the electromagnetic radiations that arrive at Earth's surface from the atmosphere, where its reflectance can be recorded and processed (Sobrino, 2000; Zhou et al., 2017). Remote detection of water body's properties, as suspended and diluted matter, is based in the interaction between the electromagnetic waves and the molecules of water and its components (Bukata et al., 2018; Domínguez et al., 2011). Sediments suspended in water produce an increase in reflection of visible radiation, varying for different particle diameters, mainly in the blue and green bands (Chuvieco, 2008). Hence, remote sensing techniques have been used to measure the SSC, through models and algorithms showing potential at regional, multi-temporal and synoptic levels; costs involved in this procedure are considerably lower than those of in situ sampling and laboratory analysis (Nooren et al., 2017; Ritchie et al., 1987; Topliss et al., 1990; Wang, 2007; Long and Pavelsky, 2013).

Algorithms for SSC quantifying can be used in some cases to predict sediment concentrations under other rivers with similar conditions (Long and Pavelsky, 2013). Some studies had developed universal algorithms to estimate suspended sediments using sensors such as MODIS and MERIS; however, such algorithms require a minimum calibration (Ritchie and Cooper, 1991; Nechad et al., 2015).

Topliss et al. (1990) developed an algorithm to quantify the SSC for concentration ranges of 5-100 and 100-1000 mg/l with the Landsat MSS sensor (bands: green, red and infrared). The data derived from Landsat 7 ETM+ and Landsat 8 OLI TIRS - the sensors employed in this study - are compatible with the data at level 1 (orthorectified) created using Landsat 1 to 5 (Ariza, 2015).

This research has three main objectives. First, to determine the validity of new generation of Landast sensors (ETM+ OLI/TIRS) using the Topliss algorithm, which was designed and calibrated for Landsat 5 MSS sensor (Topliss et al., 1990). Second, to establish the statistical relationship of the algorithm for sensor OLI with the in situ SSC measurements in the Grijalva delta and plume. The third objective was to determine the size of the sedimentary particles suspended in river and sea water in the study area, through reflectance measurements obtained in the field by spectroradiometer, and to compare them with library theoretical signatures. Depending on the reflectance percentage the spectral signature, it is possible to determine of particle size and concentration of sediment.

\section{Review of literature}

So far there are only a few works available in the literature regarding suspended sediment concentration calculus. Most of the studies and algorithms developed, using satellite imagery, were carried-out in the 2000-2010 decade. Nevertheless, between current works, we can mention:

He et al. (2013): the authors implemented a monitoring of diurnal dynamics of sediments in the ocean employing meteorological images of GOCI. The variables adjusted in the model were those related with the atmosphere. They found results with differences of less than $5000 \mathrm{mg} / 1$, except during typhoon season.

For the study areas of deltas connecting fresh water to the sea, Long and Pavelsky (2013) used MODIS imagery to determine SSC in the Peace-Athabasca, delta in 
Canada. They applied 31 empiric equations using band $1(620-670 \mathrm{~nm})$ and band 2 (841-876 nm), obtaining a Sperman's correlation of $\rho=0.95$ in 29 years of sampling.

Loisel et al. (2014) studied, over a period of 11 years, the SSC in the west of the Vietnam Sea. They used MERIS (Medium Resolution Imaging Spectrometer) data, with a spatial resolution of $300 \mathrm{~m}$. They applied three algorithms, which allowed to eliminate atmosphere interferences and to differentiate fluvial sediments from those of the sea.

Time series allowed them to recognize the season of the year with the highest SSC (Monzoon season, in September-October). In November SSC starts to decrease, and in March and May is when drier periods appear. Results obtained with MERIS imagery were satisfactory, even with the spatial resolution of 300 meters per pixel. Algorithms employed has been successfully applied in other regions of the world, and with the modifications they made on some variables, they found a correlation coefficient of 0.7 between remote sensing techniques and in situ measurements, which is a good result for a remote sensing methodology (Loisel et al., 2014).

\section{Material and methods}

\section{Study area}

The delta and plume of the Grijalva river lie to the north of the Centla Municipality, State of Tabasco, southeastern Mexico (Fig. 1), between 525221.38 and $535316.162 \mathrm{~m}$ $\mathrm{N}$ and between 2066918 and $2054176 \mathrm{~m} \mathrm{~W}$; (UTM North zone 15). The size of the study area is $\sim 60 \mathrm{~km}^{2}$, and the furthest sampling point was $10 \mathrm{~km}$ away from the coastline.

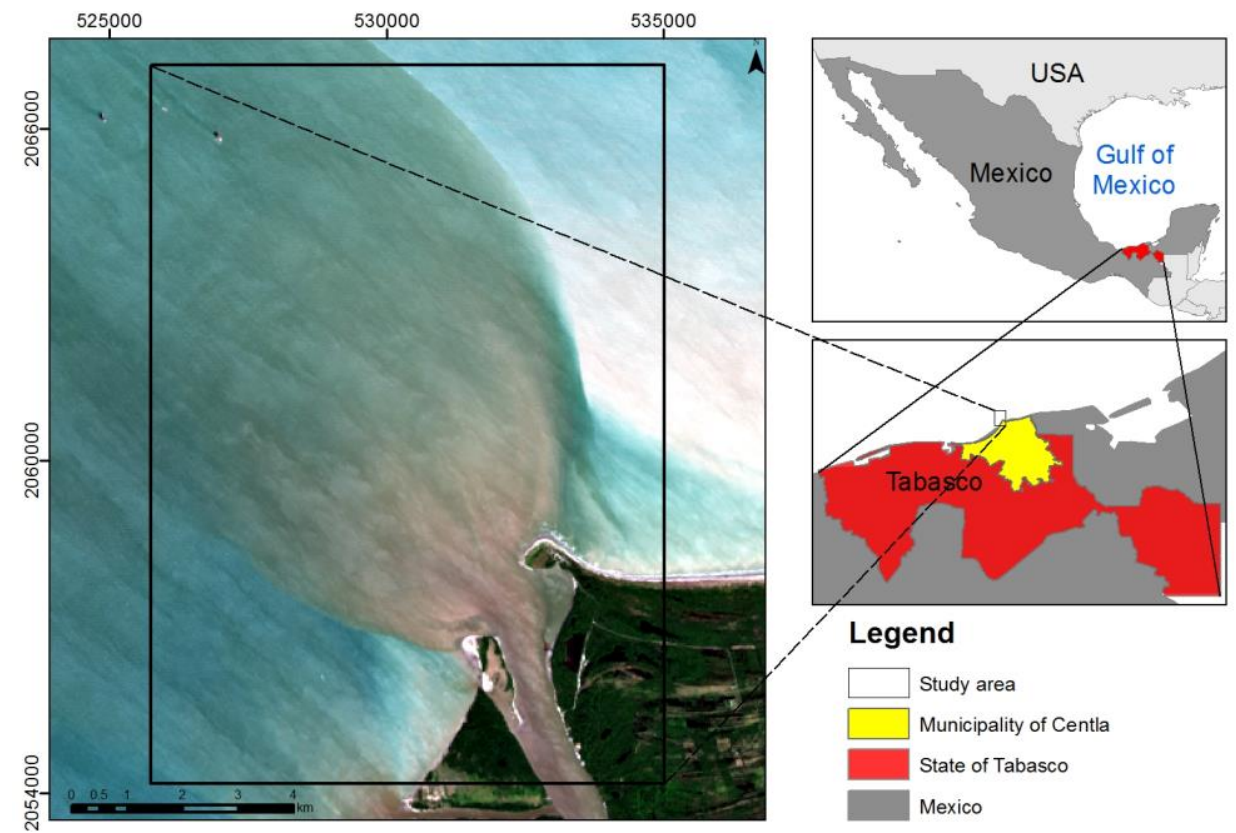

Figure 1. Plume and delta of Grijalva River, Southeast Mexico. This river flows into the Gulf of Mexico

The climate is $A m(w)$, that is, warm-humid with abundant rain in the summer, leading to marked periods of precipitation and drought (GET, 2006). Near the river 
mouth there are coastal cords, roughly parallel to the coastline, formed by sediments supplied by the Grijalva River during the last 5000 years, since the stabilization of the current sea level. Vegetation grows between the cordons formed in the water. The type of vegetation is a riparian forest of white poplar (Populus alba) and tule (Schoenoplectus acutus) (Bueno and Santiago, 2005; Nooren et al., 2017; Psuty, 1965); there are, in addition, mangrove swamps in zones nearby the river mouth.

\section{Field data gathering and laboratory analysis}

Sampling points were selected considering the dynamic distribution of sediments in the plume when entering in contact with seawater (cf. Arche, 2010), to avoid the effect of the soil and vegetation of the riverbank, with at least $1000 \mathrm{~m}$ distance between points (Fig. 2). Timing of sample collection considered the passing of the Landsat 8 satellite together with the presence of optimal meteorological conditions. Both conditions were encountered on January 25, 2016, when sampling activity was performed.

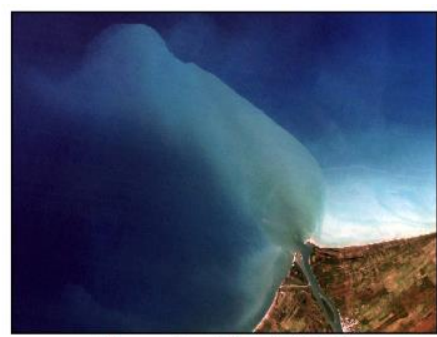

March 11, 1986

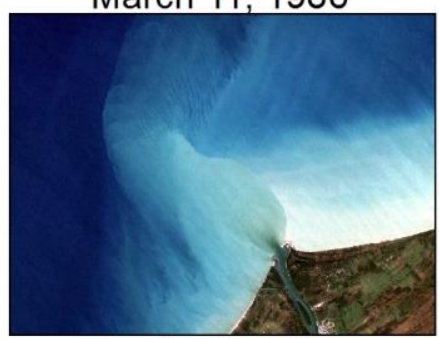

March 06, 1996

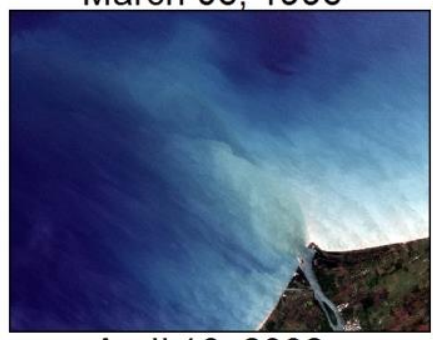

April 16, 2002

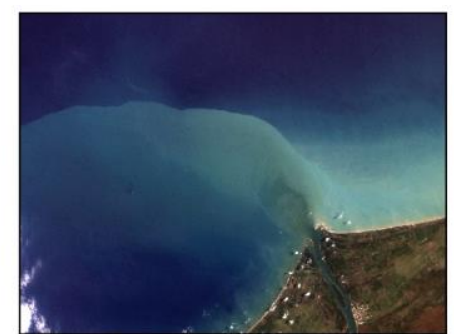

May 17,1993

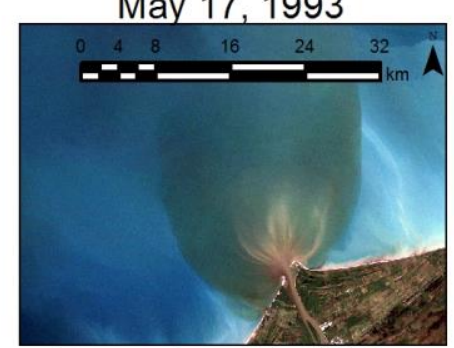

December 12, 1999

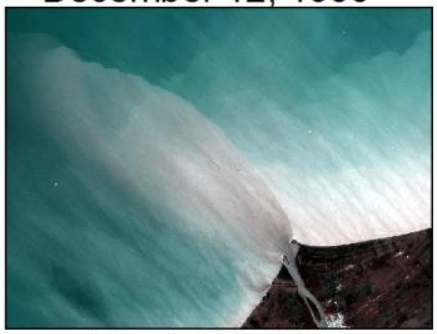

March 08, 2014

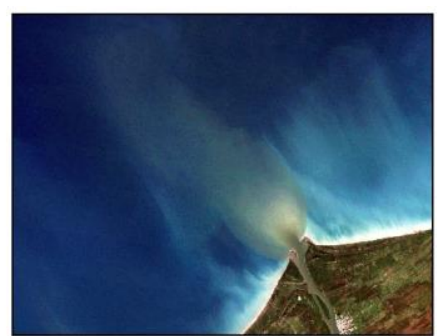

March 01, 1994

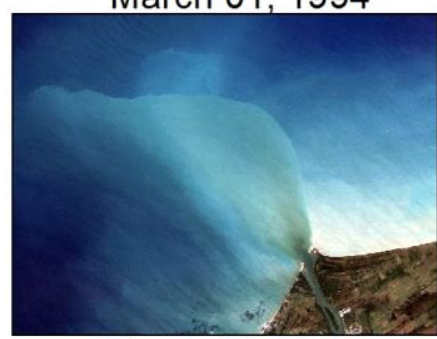

March 01, 2000

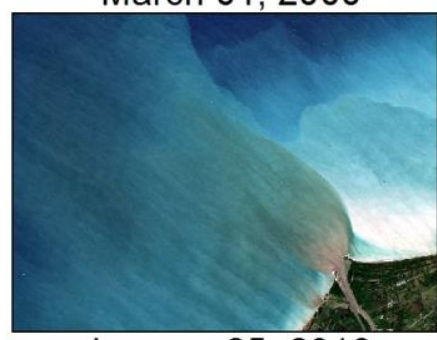

January 25,2016

Figure 2. Historical distribution of the Grijalva river plume. The last map (January 25, 2016) corresponds to the date of sampling

Samples between 0.6 and 1.01 of water were collected at a depth of 15 to $30 \mathrm{~cm}$. Depth was measured with a Speedtech instrument and spectral response of the suspended sediments with a GER-1500 spectroradiometer whose measurement range is between 296.71 and $1092.08 \mathrm{~nm}$ in intervals of $\sim 1.5 \mathrm{~nm}$ (Fig. 3).

In the laboratory, sediments were separated by a gravimetric method according to the Mexican norm NMX-AA-034-SCFI-2015. The method allows the quantitative 
measurement of the solids, dissolved solids, as well as the amount of organic matter contained in natural waters, residual, and treated wastewater.

In concordance with international standards, above mentioned norm coincides with ISO 11923:1997, Water quality - Determination of suspended solid by filtration through glass-fiber filters. However, some differences between them are found in the concepts; international method principle broaden solids determinations, drying device is different, reference suspension used has major concentration, and storage time of the sample is larger in the ISO standard. Mexican Norm maintains calculations for total suspended solids and incorporate them to another species not covered by ISO (Norma Oficial Mexicana, 2016).

Regarding the samples, every crucible with a Whatman $2 \mu \mathrm{m}$ filter had a constant weight. A vacuum pump in a flask was used to filter $100 \mathrm{ml}$ of each sample. A constant weight of sediment on a Whatman filter $(2 \mu \mathrm{m})$ in a filtering crucible was dried in a stove at $105^{\circ} \mathrm{C}$ for more than $12 \mathrm{~h}$. From the weight of the residue, the concentration of suspended solids $(\mathrm{mg} / \mathrm{l})$ was calculated. Correlation and regression analyses compared these data with those obtained by remote sensing.

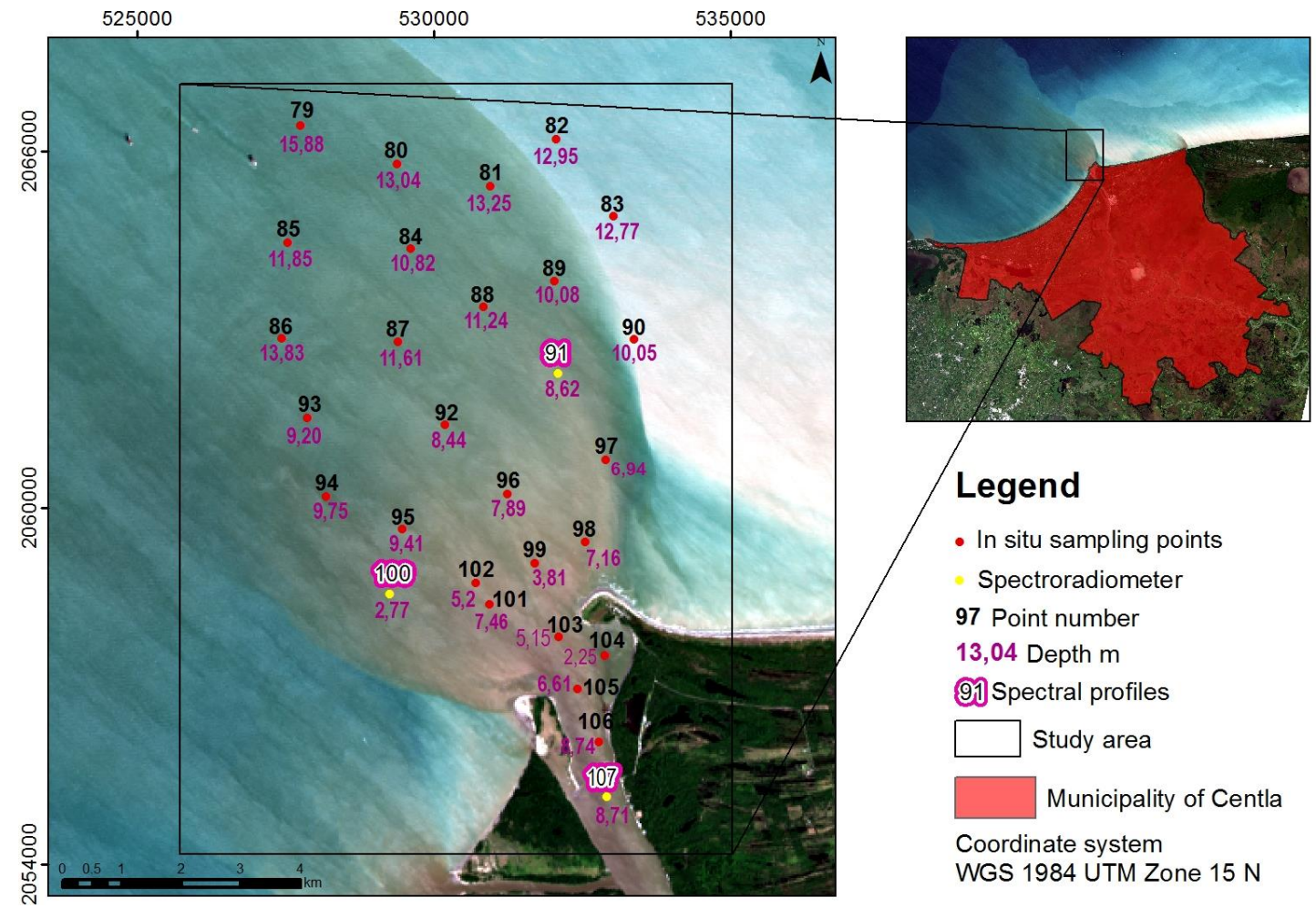

Figure 3. Distribution of sampling sites in the Grijalva river sediment plume

\section{Remote sensing data}

Satellite imagery of the study area (U.S. Geological Survey, 2016) corresponds to Path 22 and Row 47 for OLI sensor, and Path 21 Row 47 for ETM+. The ETM+ sensor revisit the same place with a difference of eight days. Imagery with adequate meteorological conditions was searched from various dates with no clouds present $(0 \%$ of clouds). The image that corresponds to the date of sampling was obtained on January 26, 2016 for Landsat 8, with the time in the central scene at 16:35:21 hours and 
February 03, 2016 with a time in the central scene at 16:13, for ETM+. Downloaded images were geometrically corrected with the cartographic projection WGS 1984 UTM zone $15 \mathrm{~N}$.

\section{Atmospheric corrections}

The atmospheric conditions affect the radiometric response of the recorded images (Richards, 2013). Radiometric and atmospheric corrections eliminate these effects and convert digital levels in physical and biophysical variables (Padró et al., 2017). In the present study, images were corrected using physical models of radiative transference, usually based on a series of standard atmospheres (Chuvieco, 2008; Sobrino, 2000).

The FLAASH method (Fast Line-of-sight Atmospheric Analysis of Spectral Hypercubes) eliminates the effects of the atmosphere, the illumination, and other factors in the reflectance of the surface, and thereby generates more precise values; it combines directly the code of atmospheric radiative transference MODTRAN4, which allows direct selection of atmospheric models such as MODTRAN standard, and the diverse types of aerosols. Furthermore, the method can be applied to correct the adjacency effect and to calculate the visibility in the whole image (Liang and Wang, 2012).

\section{Image processing}

After the atmospheric and radiometric corrections, the image was cut according to the study area. The so-called salt and pepper error was corrected applying a media filter with a $3 \times 3$ kernel.

Land covers not belonging to water were masked with the application of NDVI and NDWI indexes. In the first case the water presents values less than zero and helps in the separability; in the second one higher values correspond to the water. NDWI method is based in the quotient of the reflectance of the near-infrared and the radiation emitted in the green portion of the visible part of the electromagnetic spectrum. This enhancement minimizes the reflectance of the soil and vegetation, highlighting water bodies (Feeters, 2013). NDVI index was developed to separate the reflectance of the green portion of vegetation from any other surface. However, it was proven useful to detect water surfaces (Rokni et al., 2014).

Hence, the two indexes together allow a better separation and identification of water bodies. Finally, the algorithm proposed by Topliss et al. (1990) was applied, this being a transformation of images to generate new variables not available on the original imagery.

\section{Results}

\section{Dispersion graphics}

The correlation coefficient between the SSC obtained in the laboratory and the SSC captured from satellite imagery using the algorithm (Fig. 4a) was 0.47; thus, the relationship between the two measurements is low. The determination coefficient $\mathrm{R}^{2}$ was 0.228 , which suggests that the model explains $23 \%$ of the variance. Results from Landsat 7 were very similar, correlation coefficient was 0.52 , with a lineal coefficient $\mathrm{R}^{2}$ of 0.279 .

However, if 9 points $(80,81,83,84,87,90,91,92$ and 95) were ruled out, because they had depths less $<15 \mathrm{~cm}$. It is possible to have an interference with the basement in 
shallow depth. The correlation coefficient without the discarded samples is 0.65 , with $\mathrm{R}^{2}=0.42$; this increases the possibility of the estimation of the sediments using the algorithm, since the model here explains $42 \%$ of the variance. Results from Landsat 7 without the discarded samples were $\mathrm{R}^{2}=0.34$ and the correlation coefficient 0.58 (Fig. 4b).
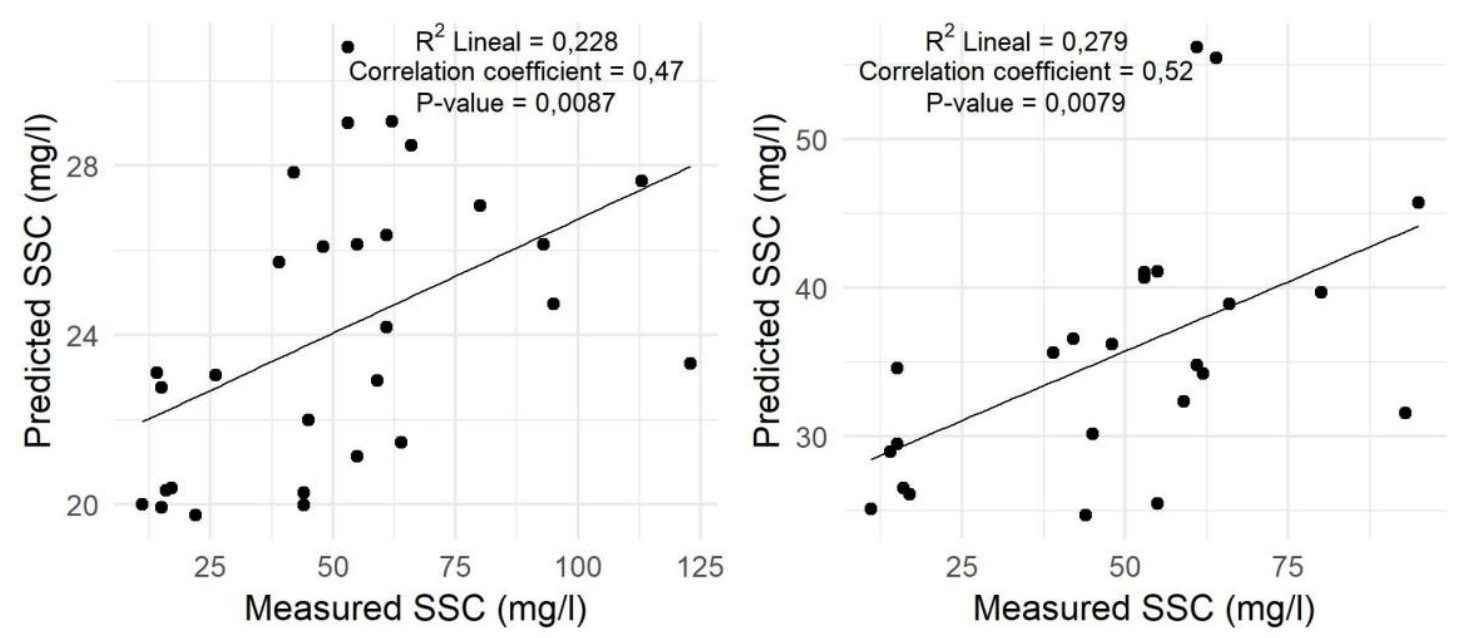

a
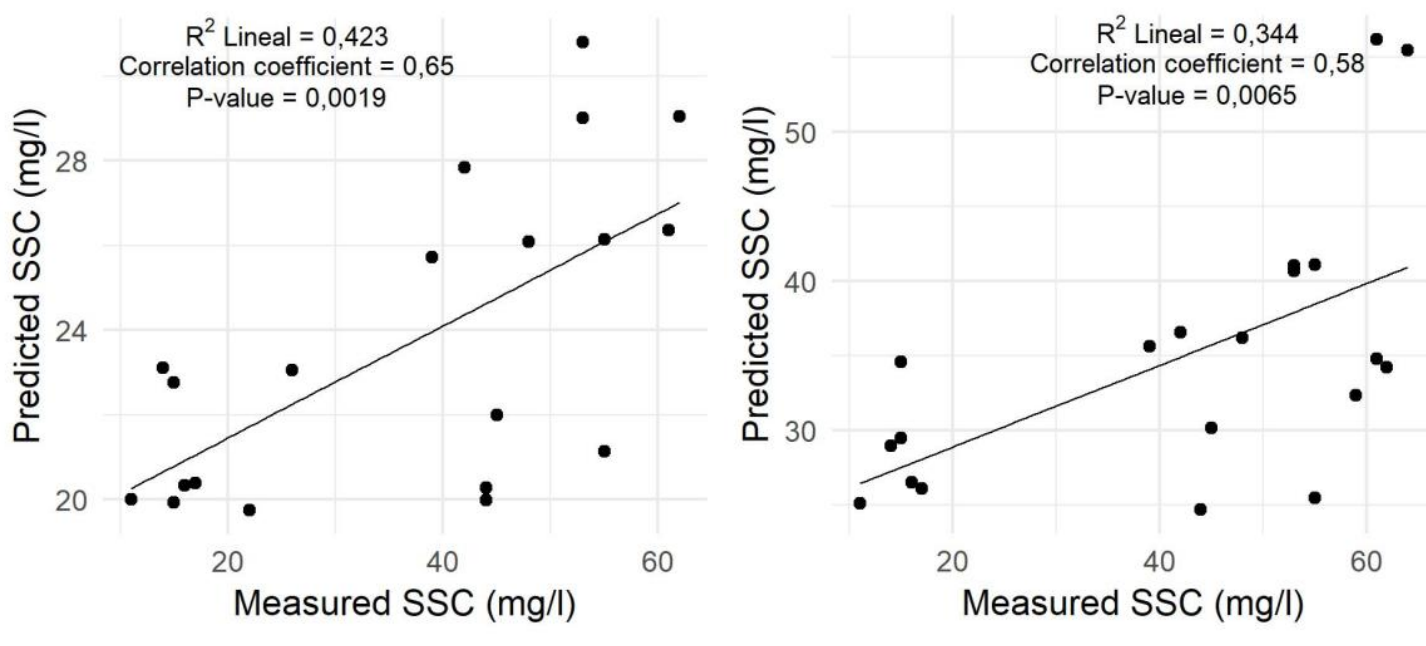

b

Figure 4. Dispersion diagrams of SSC measured in situ vs. results obtained by algorithm. $a$ Results with 29 samples. In these plots data obtained from OLI sensor (left) and from ETM+ sensor (right) are shown. $\boldsymbol{b}$ Results with 20 samples are depicted on the left with data obtained from OLI sensor and on the right with data gathered from ETM+ sensor

The mean squared root (MSR) error between the two methods was $38.71 \mathrm{mg} / \mathrm{l}$, in agreement with the poor correspondence between the algorithm results and the observations, as indicated by the correlation coefficient. When the anomalous points are omitted, the MSR error falls to $17.01 \mathrm{mg} / \mathrm{l}$. The correlation levels indicated by $\mathrm{P}$ values suggest that the test statistics are significant and that it is possible to apply the algorithms for Landsat 7 ETM+ and for Landsat 8 OLI. 


\section{Mapping SSC}

The measurements recorded in situ were geographically represented by kriging interpolation. Maps of the SSC distribution in the delta and the plume of the Grijalva River on 25 January 2016 (Fig. 5A) show concentrations to be low at the river mouth and gradually increase as the stream flows out to the open sea. The results of measurements show that SSC at points on the continental shelf are greater than those at the river mouth or in the river channel. This suggests that sediments moving along the river are transported by the water column likely near the bottom, and that when fresh water encounters seawater the difference in their densities causes former to rise, carrying the sediments up towards the surface. These sediments are subsequently distributed to form the plume of the river.

The concentration of suspended sediments measured in the laboratory (Fig. 5B) and mapped using kriging interpolation gradually increased in the direction of the open sea. Nevertheless, the result of the interpolation does not show the whole structure of the plume, particularly between $2062000 \mathrm{~N}$ and $2066464 \mathrm{~N}$, because this method estimates the data of non-sampled spaces and therefore does not adhere to the shape of the plume.

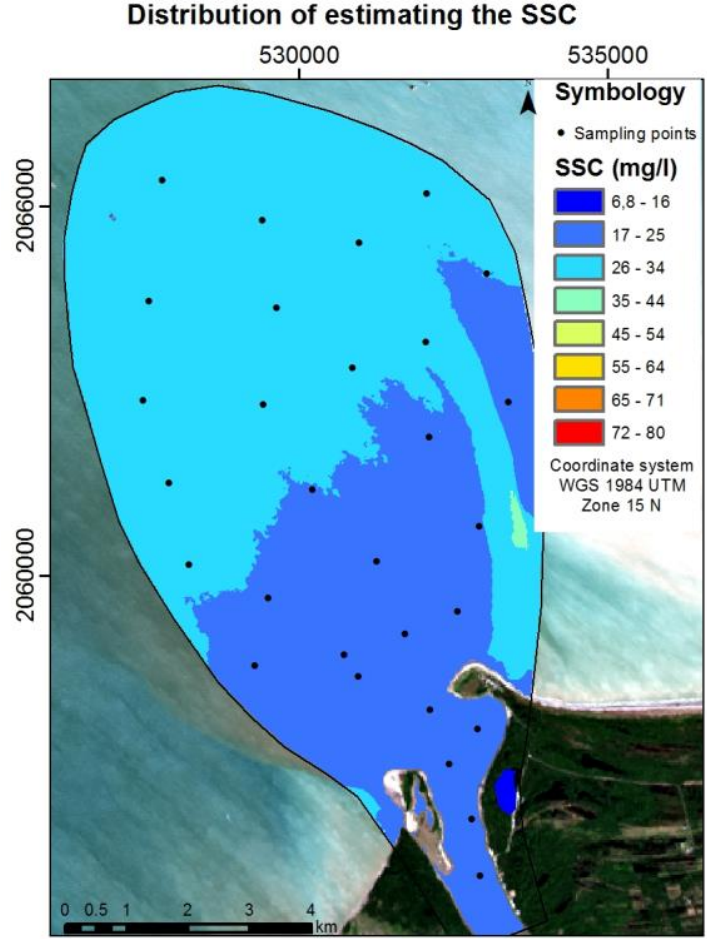

A)
Interpolating the SSC measurements in situ

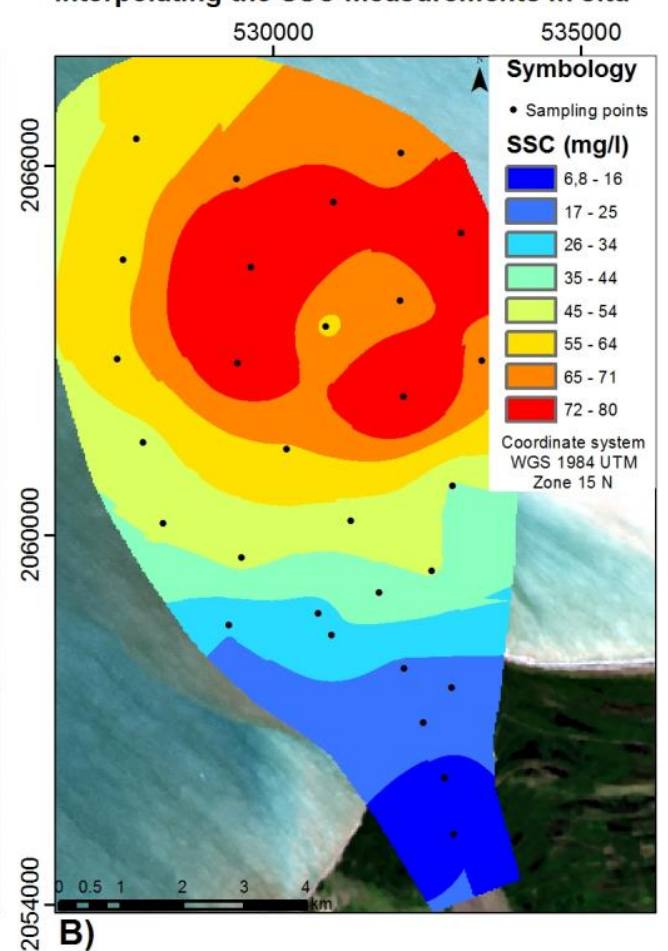

Figure 5. Cartographic representation of $(A)$ results in laboratory and $(B)$ Kriging interpolation

\section{Spectral response analysis}

In the spectral response analysis of suspended sediments, a comparison of in situ spectral signature against that one extracted from Landsat 8 was carried-out. A covariance between these two variables was found (Fig. 6). It is important to mention that the spectral response of Landsat 8 image was obtained using only seven 
atmospherically corrected bands, meanwhile with the spectroradiometer, 316 bands with intervals of approximately $1.5 \mathrm{~nm}$ were used.

Figure 6 shows the spectral responses of the five sampling sites where the spectroradiometer was used; one point with the spectral response obtained from the satellite image is located $35.5 \mathrm{~km}$ before of the end of the plume of sediments and another is in the river mouth, where the water is practically free of suspended materials (Fig. 6).

At Point 91, the spectroradiometer showed the highest reflectance (16.5\%; Fig. 6a). This sampling point also coincides with the site of the highest SSC obtained in the laboratory $(123 \mathrm{mg} / \mathrm{l})$. However, according to the theoretical signature of SSC, at this point concentration should be 600-1000 mg/l. Measured concentration from the field sample compared against theoretical signature value registered a difference of $\pm 870 \mathrm{mg} / \mathrm{l}$. At point 100 (Fig. $6 \mathrm{~b}$ ), reflectance was $8.1 \%$ and the concentration was $15 \mathrm{mg} / \mathrm{l}$, whereas the theoretical value is 100-150 mg/l (Jensen, 2007; Rose et al., 2015). In this point, measured difference in the field sample and theoretical oscillated between 85 and $135 \mathrm{mg} / \mathrm{l}$. At point 107 (Fig. 6c), reflectance was $12.5 \%$ and the concentration was $16 \mathrm{mg} / \mathrm{l}$, whereas the theoretical value is $\pm 500 \mathrm{mg} / \mathrm{l}$. Thus, difference of concentrations between field sample and theoretical value was $484 \mathrm{mg} / \mathrm{l}$. Difference between theoretical and in situ reflectance of the SSC gave a high correlation, $\mathrm{R}^{2}=0.71$.

From a comparison of in situ observations of spectral responses (Fig. 6) and theoretical signatures, the size of suspended particles can be estimated (Jensen, 2007). The measured reflectance (> 5\%) suggests that particle sizes correspond to silt or mud. However, in the response extracted from the image at a point almost at the end of the plume (Fig. $6 d$ ) reflectance is $<5 \%$, indicating that the dominant particles are clays.

\section{Discussion}

Values obtained in the measurement of the suspended sediments in the laboratory are greater than those calculated using the algorithm proposed by Topliss et al. (1990); Chen et al. (1992) found a high correlation $\left(R^{2}=0.98\right.$ with $n=29 ; R^{2}=0.83$ with $\mathrm{n}=20$ ) between the SSC and the reflectance measured in the laboratory, where the environmental effects are scarce. However, correlation between the SSC and the reflectance at the ocean surface was weak $\left(\mathrm{R}^{2}=0.46\right)$, because of the environmental effects (atmosphere, aerosols, tides etc.) (Qu et al., 2016). Data obtained in the delta of the Grijalva river using Landsat 7 and the most recent Landsat 8 satellites, has a correlation of $\mathrm{R}^{2}=0.279$ with 29 samples and $\mathrm{R}^{2}=0.334$ with 20 samples of Landsat 7 and $\mathrm{R}^{2}=0.228$ with 29 samples and $\mathrm{R}^{2}=0.423$ with 20 samples of Landsat 8 .

Results obtained for Landsat 5 with the algorithm proposed by Topliss et al. (1990), has an average correlation coefficient of $\mathrm{R}^{2}=0.70$ (Harrington et al., 1992; Ritchie and Cooper, 1991; Lodhi et al., 1998). The algorithm showed a very good correlation in lakes and the sea, but in 2013 this satellite was no longer acquiring images. Actually, Landsat 7 and Landsat 8 have similar spectral bands, which allowed us to apply the algorithm developed by Topliss et al. (1990) although the results have very low correlations for both satellites.

First calculations of sediments concentrations were based mainly on atmospheric variables due to the fact that they represented major variations in these estimations, however, between 1950 and 1970, rivers in the world with big flows started to show a 
decrement in the sediments they were transporting, this provoked that spectral responses had variations (Qu et al., 2016; Tessler et al., 2015).

In 1983 building of hydroelectric dam Chixoy, caused a decrement in the concentration of the sediments transported by the Grijalva River. Between 1983 and 2009 accumulation of sediments drop from $158 \times 10^{6} \mathrm{~m}^{3}$ to $6.1 \times 10^{6} \mathrm{~m}^{3} \mathrm{yr}^{-1}$ (Nooren et al., 2017). Nowadays, the algorithms and models developed to calculate SSC take into account changes in the spectral response of the sediments, as well as atmospheric variables (Lu et al., 2013; Qu et al., 2016; Zhang et al., 2015).

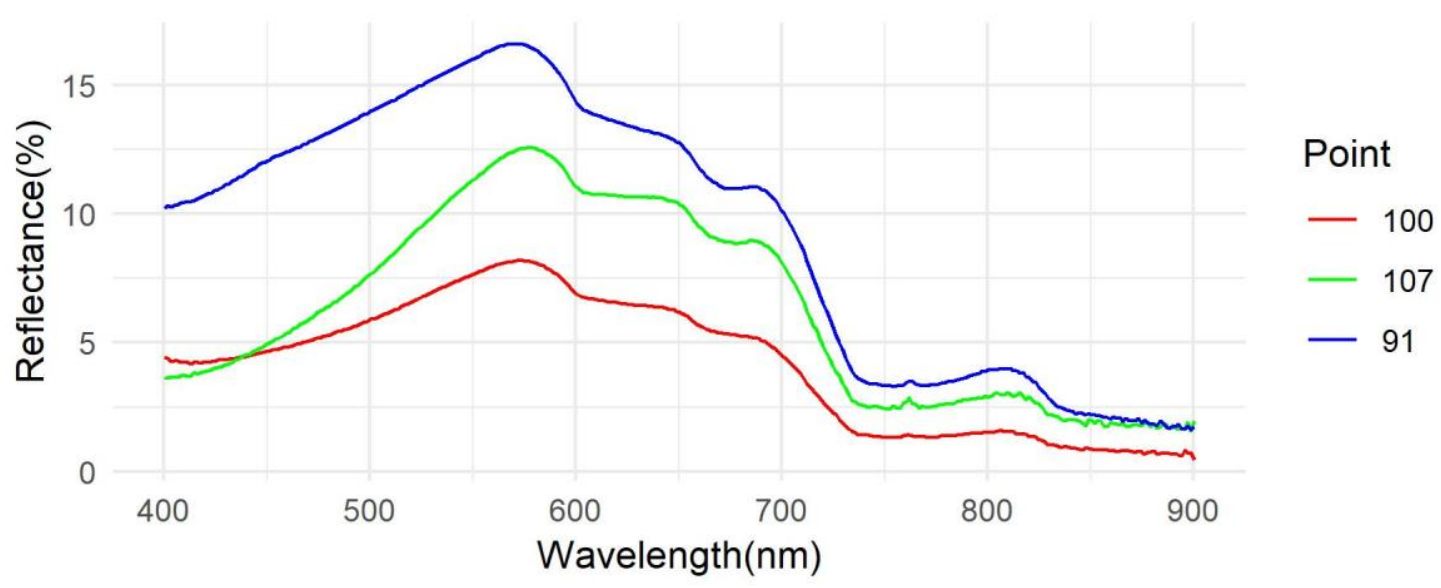

Figure 6. Three spectral responses in situ and the last spectral response using landsat 8 . The blue line is the Fig. 6a; the red line is the sample 100 is the Fig. $6 \mathrm{~b}$ and the green line is the Fig. $6 c$

In the dispersion diagram the relationship between both variables is low due the high atmospheric interference between the satellite and water surface; additionally, water vapor and aerosols are present, which causes the sensor not to detect the total reflectance of the sediments.

It is possible that the algorithm cannot be applied at latitudes far from the one for which it was proposed $\left(45^{\circ}\right.$ North). Furthermore, the climate where the algorithm was originally applied (Dfc, subpolar without dry season; and ET, tundra) differs from the tropical conditions of the present study, where suspended solids dominate. Under tundra climate bottom loading dominates (Arche, 2010). Hence, in the present study area, prediction of suspended sediments by the algorithm is less precise than that obtained in the laboratory.

Distribution analysis of the suspended sediments by kriging showed anisotropy in the river mouth because water transport usually is in one direction (Fig. 5). However, the zone with the highest SSC was distinct because the prediction suffered a circular tendency differing from the other points. Nevertheless, water discharged by a river generally has a preferred direction of flow (Arche, 2010).

The SSC can increase along the route to the open sea because a sediment wedge forms in the river mouth (Arche, 2010), where the superficial layer is fresh water brought by the river and this water column also carries suspended sediments that are subsequently exposed. The smaller particles (clays) travel a long distance before sinking to the bottom of the sea. 
The analysis of spectral responses obtained in situ with the spectroradiometer and those obtained with the bands of the image allow calculating the increase in reflectance due to suspended sediments. Likewise, determination of the size of particles in suspension allows the comparison with the signatures allocated in spectral libraries or in the literature that match a reflectance value (\%) to the SSC in $\mathrm{mg} / \mathrm{l}$ (Novo, 1989; Jensen, 2007).

Based on the reflectance, the particle size that dominates in the river mouth corresponds to silt. On the other hand, the signature extracted from the image (Fig. 6), with a reflectance value less than $5 \%$ at the end of the plume, shows that particle size that dominate are clays (Jensen, 2007). The low percentage of reflectance encountered in clayey sediments is due to the organic matter content.

According to the spectral responses measured in situ at the sampling points, concentrations are lower than those supposed to be present regarding the volume of sediments, which increase the value of the reflectance (Novo, 1989). Because of the above and the low linear relationship between both variables, there are two important points to consider:

a) Since solar radiation interacts with organic and inorganic compounds in the water, the suspended sediments in the water column should be sampled according to the penetrating capacity of the bands in the visible spectrum or at established depths down the column.

b) The relative positions of the Sun and the sensor should be considered because reflection by water surface can be specular. The sensor receives the maximum reflected energy from the surface only if it is situated in the direction of the reflection angle. In the present study the relative positions of the Sun $\left(43^{\circ}\right.$ from the horizon) and the satellite precluded measuring all the radiation reflected from the water surface. Consequently, in situ reflectance is $2-4 \%$ greater than the reflectivity of the spectral bands of the image. Therefore, the amount estimated by the algorithm is lower than that quantified in the laboratory. Additionally, local variations such as tides can suddenly change the transportation of suspended sediments.

In this study it was shown that the SSC estimation of sediments travelling in the surface can be done using bands 3 and 4 . If sampling is performed by water column, the SSC are overestimated and could be calculated using the red and infrared bands for a range of concentrations of 100 to $1000 \mathrm{mg} / \mathrm{l}$.

\section{Conclusions}

Although suspended sediments are usually quantified by in situ sampling, this task is time consuming and not economically viable for studies in remote areas. Thus, a good alternative is to use remote sensing techniques for quantification of SSC through spectral images.

This study used a spectroradiometer to obtain spectral responses in situ; real reflectance values at the water surface could be compared with values derived from the atmosphere-corrected image. Additionally, silt and clay particle size were determined in situ. Likewise, in situ reflectance indicated that most of the suspended particles were travelling in the water column rather than on the surface. 
Cartographic representation of the SSC, calculated with satellite imagery and through interpolation with in situ data, indicated a gradual increase in SSC along the route to the open sea, despite the low linear relationship between those two measurements.

For analysis of superficial sediments, according to the statistical significance obtained, the algorithm proposed by Topliss et al. (1990) can be used, with green and red bands. For sediments sampled within the water column, at concentrations exceeding $100 \mathrm{mg} / \mathrm{l}$, red and infrared bands would be used.

Taking into account the recent changes of the sedimentary regime and fluvial dynamics of the Grijalva River, the spectral responses of the sediments are mixed with the water, the shallow oceanic floor, and the predominant minerals. Therefore, it is necessary to carry-out a more extensive sampling in the study area to modify the algorithm of Toppliss et al. (1990) based in spectral mixtures of the SSC.

Acknowledgements. The authors would like to thank Ing. Hernández Ordóñez Rodrigo by the support for this publication paper.

\section{REFERENCES}

[1] Arche, A. (2010): Sedimentología del proceso físico a la cuenca sedimentaria. - Consejo Superior de Investigaciones Científicas, Madrid.

[2] Ariza, A. (2015): Instituto Geográfico Agustín Codazzi. - http://www.unspider.org/sites/default/files/LDCM-L8.R1.pdf.

[3] Bueno, J., Álvarez, F., Santiago, S. (2005): Biodiversidad del Estado de Tabasco. CONABIO, Mexico.

[4] Bukata, R. P., Jerome, J. H., Kondratyev, A. S., Pozdnyakov, D. V. (2018): Optical Properties and Remote Sensing of Inland and Coastal Waters. - CRC Press, Boca Raton.

[5] Carbonneau, P. E., Piégay, H. (2012): Fluvial Remote Sensing for Science and Management (1st Ed.). - Wiley-Blackwell, Chichester.

[6] Chen, Z., Curran, P. J., Hansom, J. D. (1992): Derivative reflectance spectroscopy to estimate suspended sediment concentration. - Remote Sensing of Environment 40(1): 6777.

[7] Chuvieco, E. (2008): Teledetección Ambiental (3rd Ed.). - Ariel, Barcelona.

[8] Domínguez-Gómez, J., Marcos-Martín, C., Chao-Rodríguez, Y., Delgado-Rojas, G., Rodríguez Pérez, D. (2011): Estudio de aguas continentales mediante teledetección. UNED, Madrid.

[9] Feeters, S. (2013): Using the normalized difference water index (NDWI) within a geographic information system to detect swimming pools for mosquito abatement: a practical approach. - Remote Sensing 5(7): 3544-3561.

[10] GET (2006): Programa de Ordenamiento Ecológico del Estado de Tabasco. Villahermosa, Gobierno del Estado de Tabasco, Tabasco.

[11] Harrington, J. A., Schiebe, F. R., Nix, J. F. (1992): Remote sensing of Lake Chicot, Arkansas: Monitoring suspended sediments, turbidity, and Secchi depth with Landsat MSS data. - Remote Sensing of Environment 29(1): 15-27.

[12] He, X., Bai, Y., Pan. D., Huang, N., Dong, X., Chen, J., Chen-Tung, A., Cui, Q. (2013): Using geostationary satellite ocean color data to map the diurnal dynamics of suspended particulate matter in coastal waters. - Remote Sensing of Environment 133: 225-239.

[13] Hernández-Santana, J. R., Ortiz-Pérez, M. A., Méndez Linares, A. P., Gama-Campillo, L. (2008): Morfodinámica de la línea de costa del estado de Tabasco, México: tendencias desde la segunda mitad del siglo XX hasta el presente. - Investigaciones Geográficas 65: 7-21. 
[14] Jensen, J. R. (2007): Remote Sensing of the Environment (2nd Ed.). - Pearson Prentice Hall, South Carolina.

[15] Kemp, G., Day, J., Yáñez-Arancibia, A., Peyronnin, N. (2016): Can continental shelf river plumes in the northern and southern Gulf of Mexico promote ecological resilience in a time of climate change. - Water 8(3) 83.

[16] Liang, S., Li, X., Wang, J. (2012): Advanced Remote Sensing: Terrestrial Information Extraction and Applications. - Academic Press, Netherland.

[17] Lodhi, M. A., Rundquist, D. C., Han, L., Kuzila, M. S. (1998): Estimation of suspended sediment concentration in water using integrated surface reflectance. - Geocarto International 13(2): 11-15.

[18] Loisel, H., Mangin, A., Vantrepotte, V., Dessailly, D., Dinh, D. N., Garnesson, P., Ouillon, S., Lefebvre, J. P., Mériaux, X., Phan, T. M. (2014): Variability of suspended particulate matter concentration in coastal waters under the Mekong's influence from ocean color (MERIS) remote sensing over the last decade. - Remote Sensing of Environment 150: 218-230.

[19] Long, C. M., Pavelsky, T. M. (2013): Remote sensing of suspended sediment concentration and hydrologic connectivity in a complex wetland environment. - Journal Remote Sensing of Environment 129: 197-209.

[20] Lu, Y., Zheng, G., Tian, Q., Lyu, C., Sun, S. (2013): Analyzing the effects of particle size on remotely sensed spectra: a study on optical properties and spectral similarity scale of suspended particulate matters in water. - Applications Optical 52(4): 879-888.

[21] Nechad, B., Ruddick, K. G., Schroeder, T., Oubelkheir, K., Blondeau-Patissier, D., Cherukuru, R. C. N., Brando, V. E., Dekker, A. G., Clementson, L. A., Banks, A. C., Maritorena, S., Werdell, J., Sa, C., Brotas, V., Caballero de Frutos, I., Ahn, Y.-H., Salama, S., Tilstone, G. H., Martinez-Vicente, V., Foley, D., McKibben, M., Nahorniak, J., Peterson, T., Silio-Calzada, A., Röttgers, R., Lee, Z. P., Peters, M., Brockmann, C. (2015): Coast Colour Round Robin datasets: a database to evaluate the performance of algorithms for the retrieval of water quality parameters in coastal waters. - Earth System Science Data 7: 319-348.

[22] Nooren, K., Hoek, W. Z., Winkels, T. G., Huizinga, A., van der Plicht, J., Van-Dam, R., Van-Heteren, S., Van-Bergen, M., Prins, M. A., Reimann, T., Wallinga, J., Cohen, K., Minderhoud, P., Middelkoop, H. (2017): The Usumacinta-Grijalva beach-ridge plain in southern Mexico: A high-resolution archive of river discharge and precipitation. - Earth Surface Dynamics 5(3): 529-556.

[23] Norma Oficial Mexicana, NMX-AA-034 (2016): Análisis de agua -Medición de sólidos y sales disueltas en aguas naturales, residuales y residuales tratadas - Métodos de prueba. Diario Oficial de la Federación, 11 de febrero de 2016, CDMX.

[24] Novo, E. M. M., Hansom, J. D., Curran, P. J. (1989): The effect of sediment type on the relationship between reflectance and suspended sediment concentration. - Remote Sensing 10(7): 1283-1289.

[25] Padró, J. C., Pons, X., Aragonés, D., Díaz-Delgado, R., García, D., Bustamante, J., Pesquer, L., Domingo-Marimon, C., González-Guerrero, Ó., Cristóbal, J., Doktor, D., Lange, M. (2017): Radiometric correction of simultaneously acquired Landsat-7/Landsat8 and Sentinel-2A imagery using pseudoinvariant areas (PIA): Contributing to the Landsat time series legancy. - Remote Sensing 9(12): 1319.

[26] Psuty, N. P. (1965): Beach-ridge development in Tabasco, Mexico 1. - Annals of the Association of American Geographers 55(1): 112-124.

[27] Qu, L., Lei, T., Ning, D., Civco, D., Yang, X. (2016): A spectral mixing algorithm for quantifying suspended sediment concentration in the Yellow River: a simulation based on a controlled laboratory experiment. - International Journal of Remote Sensing 37(11): 2560-2584.

[28] Richards, A. J. (2013): Remote Sensing Digital Image Analysis (5th Ed.). - Springer, Berlin. 
[29] Ritchie, J. C., Cooper, C. M. (1991): Algorithm for estimating surface suspended sediment concentrations with Landsat MSS digital data. - Journal of the American Water Resources Association 27: 373-379.

[30] Ritchie, J. C., Cooper, C. M., Yongqing, J. (1987): Using Landsat multispectral scanner data to estimate suspended sediments in Moon Lake, Mississippi. - Remote Sensing of Environment (23): 65-81.

[31] Rokni, K., Ahmad, A., Selamat, A., Hazini, S. (2014): Water feature extraction and change detection using multitemporal imagery. - Remote Sensing 6(5): 4173-4189.

[32] Rose, C. W., Shellberg, J. G., Brooks, A. P. (2015): Modelling suspended sediment concentration and load in a transport limited alluvial gully in northern Queensland, Australia. - Earth Surface Processes and Landforms 40(10): 1291-1303.

[33] Sobrino, A. J. (2000): Teledetección. - Universidad de Valencia, Valencia.

[34] Tessler, Z. D., Vörösmarty, C. J., Grossberg, M., Gladkova, I., Aizenman, H., Syvitski, P. M., Foufoula-Georgiou, E. (2015): Profiling risk and sustainability in coastal deltas of the word. - Science 349(6248): 638-643.

[35] Topliss, B. J., Almos, C. L., Hill, P. R. (1990): Algorithms for remote sensing of high concentration, inorganic suspended sediment. - International Journal of Remote Sensing 11(6): 947-966.

[36] Wang, J., Lu, X., Zhou, Y. (2007): Retrieval of suspended sediment concentrations in the turbid water of the Upper Yangtze River Using Landsat ETM+. - Chinese Science Bulletin 52: 273-280.

[37] Zhang, Y., Huang, Z., Chen, C., He, Y., Jiang, T. (2015): Particle size distribution of river suspended sediments determined by in situ measured remote sensing reflectance. Applied Optics 54(20): 6367-6376.

[38] Zhou, Z., Bian, C., Wang, C., Jiang, W., Bi, R. (2017): Quantitative assessment on multiple timescale features and dynamics of sea surface suspended sediment concentration using remote sensing data. - Journal of Geophysical Research: Oceans 122: 8739-8752. 